\title{
The epidemiology of malaria in adults in a rural area of southern Mozambique
}

\author{
Alfredo Mayor*1,2, John J Aponte1,2, Carole Fogg2,3, Francisco Saúte ${ }^{4}$, \\ Brian Greenwood ${ }^{3}$, Martinho Dgedge ${ }^{4}$, Clara Menendez ${ }^{1,2}$ and \\ Pedro L Alonso ${ }^{1,2}$
}

\begin{abstract}
Address: ${ }^{1}$ Center for International Health, Hospital Clinic, IDIBAPS, University of Barcelona, C/Rosello, 132, $2^{\circ} 2 \mathrm{a}$, 08036 Barcelona, Spain ${ }^{2}$ Manhiça Health Research Center, Manhiça, Mozambique, ${ }^{3}$ London School of Hygiene and Tropical Medicine, London, UK and ${ }^{4}$ National Malaria Control Programme, Ministry of Health, Mozambique

Email: Alfredo Mayor* - agmayor@clinic.ub.es; John J Aponte - jjairo@clinic.ub.es; Carole Fogg - carolefogg@yahoo.co.uk; Francisco Saúte - fsaute@dnsdee.misau.gov.mz; Brian Greenwood - brian.greenwood@lshtm.ac.uk;

Martinho Dgedge - mdgedge@dnsdee.misau.gov.mz; Clara Menendez - menendez@clinic.ub.es; Pedro L Alonso - palonso@clinic.ub.es

* Corresponding author
\end{abstract}

Published: 17 January 2007

Malaria Journal 2007, 6:3 doi:10.1186/1475-2875-6-3

This article is available from: http://www.malariajournal.com/content/6/l/3

(C) 2007 Mayor et al; licensee BioMed Central Ltd.

This is an Open Access article distributed under the terms of the Creative Commons Attribution License (http://creativecommons.org/licenses/by/2.0), which permits unrestricted use, distribution, and reproduction in any medium, provided the original work is properly cited.

\begin{abstract}
Background: Epidemiological studies of malaria in adults who live in malaria endemic areas are scarce. More attention to the natural history of malaria affecting adults is needed to understand the dynamics of malaria infection and its interaction with the immune system. The present study was undertaken to investigate the clinical, parasitological and haematological status of adults exposed to malaria, and to characterize parasites in these individuals who progressively acquire protective immunity.
\end{abstract}

Methods: A cross-sectional survey of 249 adults was conducted in a malaria endemic area of Mozambique. Clinical, parasitological and haematological status of the study population was recorded. Sub-microscopic infections and multiplicity of infections were investigated using polymerase chain reaction (PCR) and restriction fragment length polymorphism of Plasmodium falciparum merozoite surface protein 2 ( $m s p 2$ ).

Results: Prevalence of $P$. falciparum infection by microscopy (I4\%) and PCR $(42 \%)$ decreased progressively during adulthood, in parallel with an increase in the prevalence of sub-microscopic infections. Anaemia was only related to parasitaemia as detected by PCR. Multiplicity of infection decreased with age and was higher in subjects with high $P$. falciparum densities, highlighting densitydependent constraints upon the PCR technique.

Conclusion: Adults of Manhiça progressively develop non-sterile, protective immunity against $P$. falciparum malaria. The method of parasite detection has a significant effect on the observed natural history of malaria infections. A more sensitive definition of malaria in adults should be formulated, considering symptoms such as diarrhoea, shivering and headache, combined with the presence of parasitaemia. 


\section{Background}

The epidemiology of malaria in adults who live in malaria endemic areas is a neglected area of research. Malaria control strategies have focussed on children under the age of 5 years and pregnant women, as the majority of malariarelated sickness and death is seen in these two groups [1]. However, early studies in West Africa showed that clinical attacks of malaria also occur in adults living in areas of high endemicity [2] and a recent report points out the considerable contribution of malaria as a cause of death in adults [3].

The risk of malaria attacks in residents of malaria endemic areas falls as they become older [4], suggesting that protection is a function of age. This protective immunity is sequentially being reflected first by a reduction of lifethreatening disease, then by a fall in the incidence of mild malaria and finally by a reduction in parasite prevalence [5]. The means by which acquired immunity develops is still a matter of contention. It is likely that cumulative exposure to the enormous repertoire of antigenic variants of blood stage malaria parasites [6] plays an important part. However, there is evidence which suggests that protection can be established after a relatively brief period of exposure and lasts for many years $[7,8]$. Indeed, passive transfer of naturally acquired immunity [9] and malariotherapy of syphilitic patients [10] have suggested that there is a strong component of non-variant specific immunity involved in the protection against malaria which may be age-dependent.

The immune mechanisms that deal with a malarial infection probably change with age, as suggested by the agedependency of malariometric indices [11], the pyrogenic threshold of parasitaemia [12], the speed with which infections are controlled, the incidence of clinical episodes [7] and the parasitological complexity of individual infections [13]. It is generally accepted that protective immunity effectively prevents the severe clinical manifestations of Plasmodium falciparum infections and substantially reduces parasite loads, but does not prevent infection [14]. The consequence of this process is that the presence of blood-stage parasites in a semi-immune host is not synonymous with disease. This, together with the non-specificity of the malaria signs and symptoms in adults, make the individual diagnosis of clinical malaria in adults difficult in highly endemic areas.

Studies of malaria in semi-immune adults of Africa are scarce $[12,15-19]$. More attention to the natural history of malaria affecting adults is needed to understand the dynamics of malaria infection and its interaction with the immune system. The present study was undertaken to investigate the clinical, parasitological and haematological status of adults living in a region in Mozambique where malaria is endemic, and to characterize parasites in these individuals who progressively acquire protective immunity.

\section{Methods \\ Study area}

The study took place at the Manhiça Health Research Center, in Manhiça (Maputo Province), a rural area in Southern Mozambique. The area, described in detail elsewhere [20], is covered by a continuous demographic surveillance system (DSS) run by CISM since 1996. Malaria transmission is continuous, with intense seasonality. The entomological inoculation rate at the time of the study was 15 infective bites/person/year [21]. Anopheles funestus is the main vector and most infections are caused by $P$. falciparum.

\section{Cross sectional survey}

A sample of 500 adults aged $\geq 15$ years was selected randomly from the 1999 demographic census. Potential participants were invited to attend selected sites on a given date during the period 26 th July to the $4^{\text {th }}$ August 1999. Pregnant women and individuals who had taken antimalarial treatment in the week preceding sampling were excluded. After written and witnessed informed consent had been obtained, capillary blood samples were collected by finger prick for preparation of thick and thin blood films, haematocrit and filter paper blot samples (Schleicher \& Schuell number 903 ${ }^{\mathrm{TM}}$ filter paper, Dassel, Germany). Axillary temperature and details of symptoms potentially due to malaria (reported fever, headache, body pain, shivering, nausea, vomiting, abdominal pain and diarrhoea) were recorded. Results of blood film examination and the haematocrit were sent to participants within two days of sampling, and medical advice and treatment were given when necessary.

\section{Laboratory methods}

Blood slides were processed and read according to qualitycontrolled procedures as described elsewhere [22]. Haematocrit values were determined in a microcapillary after centrifugation for $5 \mathrm{~min}$ at $9000 \mathrm{~g}$. All samples positive by light microscopy, those with a haematocrit less than $33 \%$, and $30 \%$ of the remaining negative slides, were analysed by polymerase chain reaction (PCR) for $m s p 2$ and restriction-fragment length polymorphism (RFLP). A piece corresponding to approximately $1 / 8^{\text {th }}$ of the blot on the filter paper was used for a nested PCR amplification of $m s p 2$ and genotyping by restriction with enzymes as described elsewhere [23]. A negative control, to which no DNA had been added, and a positive control, to which $P$. falciparum clone 3D7 DNA (50 ng) had been added were included in each set of amplification reactions. 


\section{Data analysis}

Data were double entered using Visual Fox Pro 5.0 and statistical analyses were performed using Stata5. Fever was defined as an observed axillary temperature $\geq 37.5^{\circ} \mathrm{C}$ and/ or patient-reported fever within the previous $24 \mathrm{~h}$. Clinical malaria was defined as fever with a positive blood slide for asexual $P$. falciparum parasites. Anaemia was defined as a haematocrit $<33 \%$. The summary measures consisted of percentage for categorical variables and means for continuous variables. Parasite densities are reported as the geometric mean of parasite-positive samples. The prevalence of sub-microscopic infections was calculated as the number of the PCR-positive samples which had been negative by microscopic examination divided by the total number of PCR-positive samples. Multiplicity of infection (MOI) was defined as the number of distinct msp2-genotypes detected in infected samples. Student's t-test and linear regression were used to assess differences between quantitative variables. The age trends of the different categorical variables were assessed using the Chi-square test for linear trend. The association between parasite density and MOI was calculated separately for each age group by multiple regression analysis. Categorical variables such as sex, positivity by PCR and microscopy, anaemia and presence or absence of symptoms were analysed using Chisquare and logistic regression. A p-value of 0.05 was considered statistically significant. Sensitivity and specificity of the malaria case definition was evaluated using the attributable fraction of fever due to malaria as described elsewhere [24].

\section{Ethical clearance}

This study fell within the national clearance granted in 1996 to the malaria epidemiology studies of the Manhiça Health Research Center by the Ministry of Health/ National Institute of Health of Mozambique.

\section{Results}

Among the 500 names selected from the census, 137 were not traceable. Eleven of the remainder had taken antimalarials, 12 were pregnant and 91 were absent on the day of the survey. Thus, the study included 249 adults whose mean age was 37 years (range 15 to 83 years). In concordance with the overall sex distribution of the adult population in the area, two thirds of the subjects were female.

Parasitaemia as detected by microscopy was found in $14.4 \%$ of subjects $(36 / 249)$. All infections were due to $P$. falciparum. Only one subject had gametocytes. Prevalence of parasitaemia by microscopy decreased significantly with increasing age $(\mathrm{p}<0.001)$ (Figure 1$)$. The geometric mean parasite density was 336 parasites/ $\mu$ l (range 32 to 20376 parasites/ $\mu \mathrm{l}$ ), and also decreased with age, but this relation was not significant $(\mathrm{p}=0.31)$ (Figure 1$)$.
A total of 180 samples, selected as defined above, were analysed by PCR. The prevalence of $P$. falciparum infection determined by PCR was $42 \%$, and significantly decreased with age $(\mathrm{p}<0.001)$ (Figure 1$)$. The proportion of submicroscopic infections increased significantly with age $(\mathrm{p}$ $=0.02$ ) (Figure 1). A small number (8.3\%) (3/36) of the parasite positive samples by microscopy were negative by PCR while 34.7\% (50/144) of the samples negative by light microscopy were positive by PCR. The specificity of light microscopy was $96.9 \%$ but the sensitivity only $37.5 \%$.

All PCR-positive samples were analysed for MOI by RFLP. Of these $50.6 \%$ (41/81) consisted of a single msp2 genotype, $23.5 \%$ were double infections, $14.8 \%$ triple, $9.9 \%$ quadruple, and a quintuple infection. The mean MOI was 1.9. There was an inverse association between age and MOI ( $\mathrm{p}=0.009)$ (Figure 1). Doubling the age, reduced the MOI by $20.0 \%$. Subjects with microscopically detectable parasites were more likely to have multiple infections than those who were just PCR positive ( $\mathrm{p}=0.010)$. After adjusting for age, there was a positive association between parasite density and MOI $(\mathrm{p}=0.001)$. Every new infection increased the mean geometric parasite density by a factor of 1.98 .

The mean axillary temperature was $36.1^{\circ} \mathrm{C}$ (range $35.1^{\circ} \mathrm{C}$ to $37.3^{\circ} \mathrm{C}$ ). None of the adults had fever at the moment of the examination. No significant associations were found between mean temperatures and the prevalence of any symptom, but a significant inverse relationship was found between age and temperature. Doubling age decreased temperature by $0.05^{\circ} \mathrm{C}(\mathrm{p}=0.004)$. Prevalences of symptoms are shown in Table 1.

Anaemia (haematocrit < 33\%) was found in 9.8\% (24/ 245 ) of the subjects (in 4 the haematocrit could not be measured). Twenty-two of the 24 anaemic subjects were females. Haematocrit values were not related to age ( $\mathrm{p}=$ 0.5). After adjusting for sex, PCR positive subjects had a haematocrit $2.0 \%$ lower than the PCR negative subjects ( $\mathrm{p}$ $=0.002)$.

Clinical malaria, as defined above, was found in $2.4 \%$ of the subjects (6/249). The estimated attributable fraction of fever due to malaria was $6.7 \%$. The specificity of our definition was estimated as $91 \%$ (95\% CI $81 \%$ to $98 \%$ ). Among parasitaemic adults, there was a significant association between high parasite densities and the presence of diarrhoea $(\mathrm{p}=0.004)$ or headache $(\mathrm{p}=0.014)$, and an inverse association between shivers and parasite density $(\mathrm{p}=0.029)$. No relationship was found between MOI and any symptom. 

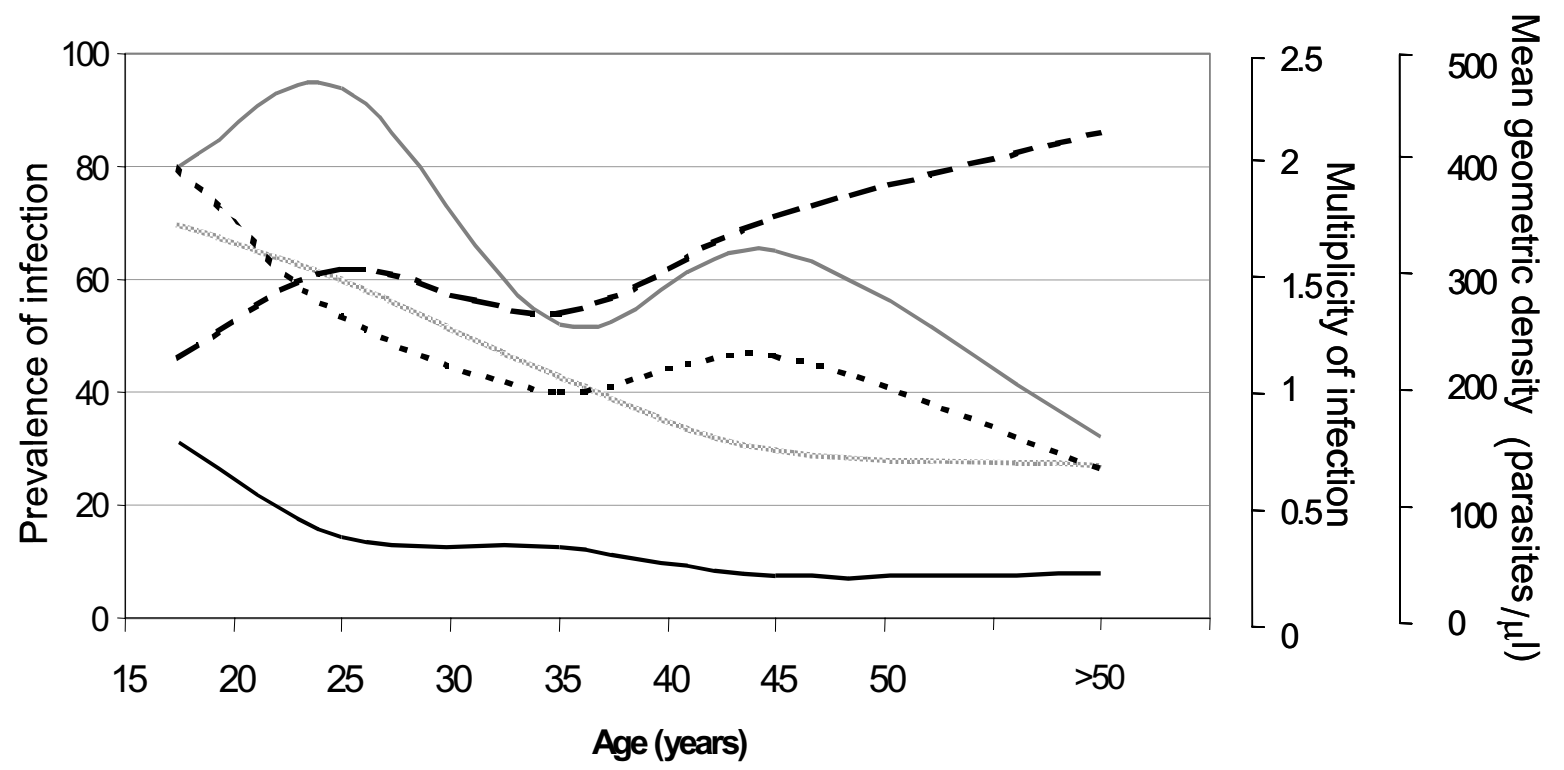

\begin{tabular}{|l}
\hline _ Prevalence by microscopy \\
_ Log Density \\
— - Prevalence of submicroscopic infections
\end{tabular}

\section{Figure I}

Prevalence of Plasmodium falciparum infection as determined by microscopy or PCR, proportion of sub-microscopic infections, mean geometric density and multiplicity of infection by age in adults from Manhiça.

\section{Discussion}

This study, one of the few focussing on malaria in adults from a malaria hyperendemic area [7,12,15-19], has shown a high discordance between $P$. falciparum prevalence as determined by microscopy (14\%) and PCR $(42 \%)$. Estimates of infection determined by microscopy are probably unreliable in adults because of the high prevalence of $P$. falciparum infections with densities below the detection threshold of blood film examination. Even prevalence of PCR detected parasites and MOI may be underestimated when parasites reach such low levels that densities fluctuate around the threshold limit of the PCR [25]. This interpretation is supported by the densitydependent constraints of the PCR found in our study; multiple $P$. falciparum clones are differentiated more efficiently in high-density infections.

The abundance of sub-microscopic infections in adults from Manhiça and the low specificity of signs and symptoms hamper the definition of a malaria episode. Fever was not detected at the time of examination in any of the adults in this study. Other symptoms such as diarrhoea, shivering and headache, combined with the presence of parasitaemia, could be used to formulate a more sensitive definition of malaria in adults. Special emphasis should be paid to anaemia. In our study area, the significantly higher frequency of anaemia cases among PCR positive individuals might have been due to a reduction in haema- 
Table I: Prevalence of symptoms and signs in the study population $(n=249)$.

\begin{tabular}{lc}
\hline SYMPTOM/SIGN & Prevalence (\%) \\
\hline Individual symptoms & \\
Reported fever & 15.7 \\
Headache & 23.3 \\
Body pain & 14.1 \\
Shivering & 12.1 \\
Nausea & 12.9 \\
Vomiting & 5.6 \\
Abdominal pain & 37.4 \\
Diarrhoea & 6.8 \\
Number of symptoms experienced & \\
No symptoms & 48.6 \\
One symptom & 24.9 \\
2/3 symptoms & 12.5 \\
$4+$ symptoms & 14.1 \\
Signs & \\
Fever & 0
\end{tabular}

tocrit because of recent high density infections that have been controlled at the moment of the examination by an efficient immunity or prior treatment. Alternatively, it may have been the result of persistent asymptomatic infections that significantly increase the risk of becoming anaemic.

During the dry season, almost half of the adults from Manhiça were infected by $P$. falciparum, as detected by PCR. Parasite rate might be even higher during the wet season. Studies in other settings have found similar high prevalences [25], showing that cumulative prevalence of parasite carriers over a year is close to $100 \%$ [26]. This prevalent carriage of parasites can be due to a chronic nature of malaria infections, or to frequent reinfections which only reach low blood-stage densities before being eliminated. Most of the infections in our study subjects were asymptomatic, indicating the occurrence of host immunity able to restrict parasites to low densities with a sub-clinical course, although these immune mechanisms cannot achieve permanent sterility. Importantly, immunity seems to develop during the whole life, as suggested by the continuous increment in the prevalence of submicroscopic infections and the trend towards a reduction of parasite densities, which may not reach statistical significance because of the impossibility to assign accurate densities to sub-microscopic infections by conventional PCR methods.

Two forms of antimalarial immunity are believed to occur, an anti-disease and an anti-parasite immunity [27]. The first one, reflected by the age evolution of fever, is believed to develop rapidly, reducing the frequency of clinical presentation of malaria. The second is said to be slowly acquired, leading to a progressive decrease in parasite prevalence and MOI. However, the immune ability to control the parasite may be better reflected by parasite densities rather than by the prevalence of parasites. We have reported previously that in the Manhiça district of Mozambique, both parasite densities and incidence of clinical malaria decline in parallel during the second half of infancy $[28,29]$, suggesting that immune mechanisms able to control parasite densities result in less severe symptoms. In this community anti-disease and anti-parasite immunity seem to develop concomitantly and do not necessarily reflect two different aspects of the host defence mechanisms against malaria.

\section{Conclusion}

This study has evidenced the abundance of sub-microscopic infections in adults from Manhiça. Estimates of infection determined by microscopy are probably unreliable, suggesting that the method of parasite detection may have a significant effect on the observed natural history of malaria infections in adults. The increment with age in the prevalence of sub-microscopic infections, together with the trend towards a reduction of parasite densities, suggests that immunity in adults develops during the whole life. This immunity is able to restrict $P$. falciparum parasites to low densities with a sub-clinical course, but is not sterilizing. A more sensitive definition of malaria in adults should be formulated, considering other symptoms such as diarrhoea, shivering and headache, combined with the presence of parasitaemia.

\section{Authors' contributions}

AM carried out the molecular genotyping study, the analysis and interpretation of data and prepared the manuscript. JA carried the statistical analysis and helped to draft the manuscript. CF carried out the sample collection and contributed to the analysis and interpretation of data. FS, BG and MD contributed to the interpretation of the data and drafting of the paper. CM and PA conceived and coordinated the study, participated in the analysis and interpretation of the data, and contributed to the preparation of the manuscript. All authors read and approved the final manuscript.

\section{Acknowledgements}

We are indebted to the adults participating in the study. The work of the clinical officers, field supervisors, data manager, and laboratory coordinator was important for the successful completion of the study. We thank Xavier Gomez-Olive for his contribution to the conduction of the study and to Caterina Guinovart for her comments on the manuscript. This investigation received financial support from the Spanish Agency for International Cooperation (AECI). AM was supported by the Spanish Ministry of Health (Program for the Promotion of Biomedical Research and Health Sciences, Carlos III Health Institute, CP-04/00220). 


\section{References}

I. Snow RW, Guerra CA, Noor AM, Myint HY, Hay SI: The global distribution of clinical episodes of Plasmodium falciparum malaria. Nature 2005, 434:214-217.

2. Miller MJ: Observations on the natural history of malaria in the semi-resistant West African. Trans R Soc Trop Med Hyg 1958, 52:152-168.

3. Adjuik M, Smith T, Clark S, Todd J, Garrib A, Kinfu Y, Kahn K, Mola M, Ashraf A, Masanja H, Adazu K, Sacarlal J, Alam N, Marra A, Gbangou A, Mwageni E, Binka F: Cause-specific mortality rates in sub-Saharan Africa and Bangladesh. Bull World Health Organ 2006, 84: $181-188$.

4. Koch R: Zweiter bericht über die thatigkeit der malaria expedition. Deutsche Med Wochenschr 1900, 26:88-90.

5. Snow RW, Nahlen B, Palmer A, Donnelly CA, Gupta S, Marsh K: Risk of severe malaria among African infants: direct evidence of clinical protection during early infancy. J Infect Dis 1998, 177:819-822.

6. Bull PC, Lowe BS, Kortok M, Molyneux CS, Newbold CI, Marsh K: Parasite antigens on the infected red cell surface are targets for naturally acquired immunity to malaria. Nat Med 1998, 4:358-360.

7. Baird JK, Jones TR, Danudirgo EW, Annis BA, Bangs MJ, Basri H, Purnomo , Masbar S: Age-dependent acquired protection against Plasmodium falciparum in people having two years exposure to hyperendemic malaria. Am J Trop Med Hyg 1991, 45:65-76.

8. Lepers JP, Andriamangatiana-Rason MD, Ramanamirija JA, Fontenille $D$, Lepers $C$, Deloron $P$, Coulanges $P$ : [Malaria in 1988 in a village of the Malagasy Highland Plateaux. Epidemiological findings]. Arch Inst Pasteur Madagascar 1989, 56:97-130.

9. McGregor IA: The passive transfer of human malarial immunity. Am J Trop Med Hyg 1964, I3(Suppl):237-239.

10. Jeffery GM: Epidemiological significance of repeated infections with homologous and heterologous strains and species of Plasmodium. Bull World Health Organ 1966, 35:873-882.

I I. Smith T, Felger I, Tanner M, Beck HP: Premunition in Plasmodium falciparum infection: insights from the epidemiology of multiple infections. Trans R Soc Trop Med Hyg 1999, 93:59-64.

12. Rogier C, Commenges D, Trape JF: Evidence for anage-dependent pyrogenic threshold of Plasmodium falciparum parasitemia in highly endemic populations. Am J Trop Med Hyg 1996, 54:613-619.

13. Smith T, Beck HP, Kitua A, Mwankusye S, Felger I, Fraser-Hurt N, Irion A, Alonso P, Teuscher T, Tanner M: Age dependence of the multiplicity of Plasmodium falciparum infections and of other malariological indices in an area of high endemicity. Trans $R$ Soc Trop Med Hyg 1999, 93: 15-20.

14. Sergent E, Parrot L: L'immunité. La prémunition et la résistance innée. Archives de I'Institut Pasteur d'Algérie 1935, I3:279-319.

15. Trape JF, Peelman P, Morault-Peelman B: Criteria for diagnosing clinical malaria among a semi-immune population exposed to intense and perennial transmission. Trans R Soc Trop Med Hyg 1985, 79:435-442.

16. Petersen E, Hogh B, Marbiah NT, Dolopaie E, Gottschau A, Hanson $A P, B j o r k m a n A$ : Clinical and parasitological studies on malaria in Liberian adults living under intense malaria transmission. Ann Trop Med Parasitol 1991, 85:577-584.

17. Elhassan IM, Hviid L, Jakobsen PH, Giha H, Satti GM, Arnot DE, Jensen JB, Theander TG: High proportion of subclinical Plasmodium falciparum infections in an area of seasonal and unstable malaria in Sudan. Am J Trop Med Hyg 1995, 53:78-83.

18. Roper C, Elhassan IM, Hviid L, Giha H, Richardson W, Babiker H, Satti GM, Theander TG, Arnot DE: Detection of very low level Plasmodium falciparum infections using the nested polymerase chain reaction and a reassessment of the epidemiology of unstable malaria in Sudan. Am J Trop Med Hyg 1996, 54:325-33I.

19. Hamad AA, El Hassan IM, El Khalifa AA, Ahmed GI, Abdelrahim SA, Theander TG, Arnot DE: Chronic Plasmodium falciparum infections in an area of low intensity malaria transmission in the Sudan. Parasitology 2000, I 20:447-456.

20. Alonso P, Saute F, Aponte JJ, Gomez-Olive FX, Nhacolo A, Thomson $R$, Macete E, Abacassamo F, Ventura PJ, Bosch X, Menendez C, Dgedge M: Manhica DSS, Mozambique. In INDEPTH Network ed. Population, Health and Survival at INDEPTH Sites Volume I. Ottawa: International Development Research Centre; 2001:189-195.
21. Aranda C, Aponte JJ, Saute F, Casimiro S, Pinto J, Sousa C, Rosario VD, Petrarca V, Dgedge M, Alonso P: Entomological characteristics of malaria transmission in Manhica, a rural area in southern Mozambique. J Med Entomol 2005, 42:180-186.

22. Alonso PL, Smith T, Schellenberg JR, Masanja H, Mwankusye S, Urassa $\mathrm{H}$, Bastos de Azevedo I, Chongela J, Kobero S, Menendez C, Hurt N, Thomas MC, Lyimo E, Weiss NA, Hayes R, Kitua AY, Lopez MC, Kilama WL, Teuscher T, Tanner M: Randomised trial of efficacy of SPf66 vaccine against Plasmodium falciparum malaria in children in southern Tanzania. Lancet 1994, 344: I I75- I I8I.

23. Felger I, Tavul L, Beck HP: Plasmodium falciparum: a rapid technique for genotyping the merozoite surface protein 2 . Exp Parasitol 1993, 77:372-375.

24. Smith T, Schellenberg JA, Hayes R: Attributable fraction estimates and case definitions for malaria in endemic areas. Stat Med 1994, I 3:2345-2358.

25. Bottius E, Guanzirolli A, Trape JF, Rogier C, Konate L, Druilhe P: Malaria: even more chronic in nature than previously thought; evidence for subpatent parasitaemia detectable by the polymerase chain reaction. Trans $R$ Soc Trop Med Hyg 1996, 90:15-19.

26. Trape JF, Rogier C, Konate L, Diagne N, Bouganali H, Canque B, Legros F, Badji A, Ndiaye G, Ndiaye P, Brahini K, Faye O, Druilhe P, Pereira da Silva L: The Dielmo project: a longitudinal study of natural malaria infection and the mechanisms of protective immunity in a community living in a holoendemic area of Senegal. Am J Trop Med Hyg 1994, 5 I: I23-137.

27. Playfair JH, Taverne J, Bate CA, de Souza JB: The malaria vaccine: anti-parasite or anti-disease? Immunol Today 1990, I I:25-27.

28. Saute F, Aponte J, Almeda J, Ascaso C, Abellana R, Vaz N, Dgedge M, Alonso P: Malaria in southern Mozambique: malariometric indicators and malaria case definition in Manhica district. Trans R Soc Trop Med Hyg 2003, 97:661-666.

29. Saute F, Aponte J, Ahmeda J, Ascaso C, Vaz N, Dgedge M, Alonso P: Malaria in southern Mozambique: incidence of clinical malaria in children living in a rural community in Manhica district. Trans R Soc Trop Med Hyg 2003, 97:655-660.
Publish with Bio Med Central and every scientist can read your work free of charge

"BioMed Central will be the most significant development for disseminating the results of biomedical research in our lifetime. "

Sir Paul Nurse, Cancer Research UK

Your research papers will be:

- available free of charge to the entire biomedical community

- peer reviewed and published immediately upon acceptance

- cited in PubMed and archived on PubMed Central

- yours - you keep the copyright

Submit your manuscript here:

http://www.biomedcentral.com/info/publishing_adv.asp
BioMedcentral 